\title{
OPTIMIZATION OF WORKLOAD DISTRIBUTION TECHNIQUE TO INCREASE THE LINE EFFICIENCY OF BAKERY OVEN MANUFACTURING UNIT
}

\author{
S Bharath ${ }^{1}$, Pavan Kumar SJ² \\ ${ }^{1}$ Associate Professor Department of IEM, MS Ramaiah Institute of Technology, Bengaluru \\ ${ }^{2}$ PG Student Dept of IEM, MS Ramaiah Institute of Technology, Bengaluru
}

\begin{abstract}
A sequential construction system is an assembling procedure (more often than not called a dynamic get together) in which parts are included as the semi-completed gathering moves from workstation to workstation where the parts are included arrangement until the last get together is delivered. By mechanically moving the parts to the get together work and moving the semi-completed get together from work station to work station, a completed item can be collected speedier and with less work than by having laborers convey parts to a stationary piece for gathering.
\end{abstract}

A study was completed in ABC Company which makes broilers. It was observed that machines utilized there are using more opportunity for delivering stoves. This generation the truth will surface eventually lessened by utilizing modern designing method called work streamlining in the mechanical production system which takes care of the genuine issue, the undertaking time information and sitting tight time information was gathered for all the nine phases of the get together and further the outcomes were gotten.

The line productivity subsequent to gathering the work station is expanded from $43.07 \%$ to $79 \%$. Furthermore, the parity delay diminishes from $56.2 \%$ to $21 \%$. This makes work load conveyance uniform over the workstations which make the stream of the sequential construction system much smooth. Subsequent to expanding the line proficiency and diminishing the equalization defer the profitability has expanded and now the stoves are fabricated in a less time contrasted with before time. What's more, genuine issue was illuminated.

Keywords: Assembly line, work optimization, line efficiency, balances delay. ***.

\section{INTRODUCTION}

A sequential construction system comprises of number of workstations which are organized along a transport line or comparable material transportation hardware, with a specific end goal to get a succession of completed item sorts the work pieces are moved from stations. Certain operations are performed in the perspective of a few limitations. The main essential limitation is the process duration. The process duration is the time interim between completing two units or most extreme accessible time for the creation of any work piece at any workstation. Get together lie exists when we amass or handle any gadget or item in an arranged, consecutive way with two or more operations performing errands of dull work at a built up workstation. In the sequential construction system, specialists do their work in their particular workstation. On the off chance that the laborer finishes his work and past specialist has not finished, he needs to hold up. With a specific end goal to maintain a strategic distance from this holding up time gathering of workstation is done as such that specific number of workstations can be assembled and the unmoving time can be decreased.
Steps in grouping workstations

- Find out the work exercises arrangement and record the perceptions, for example, process duration, undertaking time and holding up time.

- Calculate the execution benefit of existing workstations by utilizing formulae.

- Find the work load at every workstation to check its variety over the workstations. The work burden can be gotten by duplicating number of specialists and the undertaking time of the particular workstation.

-Group the workstations till the undertaking times of gathered workstations comes to close to the process duration of the mechanical production system. Note that the undertaking time of gathered workstations ought to never cross the process duration of the mechanical production system.

- Calculate the execution estimations of gathered workstations and note down the outcomes.

\section{LITERATURE REVIEW}

As indicated by Scholl and Becker[1], sequential construction system is an arrangement of dynamic get together station connected by material taking care of 
gadgets. Sequential construction system is an extraordinary instance of item format in which operations relate to get together of various parts at few stations.

The goals of single model sequential construction systems are

- Minimizing the quantity of stations for a given process duration

- Minimizing the process duration for a given number of stations

- Minimizing the parity delay time (total of unmoving times) and the parity delay (rate of unmoving times) over all stations.

A work was exhibited by SotinosDimitriadis[2], on sequential construction system adjusting and gather working with a heuristic strategy for laborers in gatherings working on the same item and workstation.

As per Nils Bovsen and MalteFliedner[3], adjusting mechanical production systems is an essential mission for assembling commercial ventures with a specific end goal to enhance profitability by minimizing the process duration or the quantity of workstations.

As per Helgeson and Birnie in [4], Ranked positional weight technique (RPW) is a worth to be processed for every component in the framework.

Steps in RPW method.

1. Draw the priority chart

2. For every work component, decide the positional weight. It is the aggregate time on the longest way from the earliest starting point of the operation to the last operation of the system

3. Rank the work components in sliding request of RPW. Estimation of RPW would be disclosed in the case to take after.

4. Assign the work component to a station. Pick the most elevated RPW component. At that point, select the following one. Proceed till process duration is not disregarded. Take after the priority limitations too.

5. Repeat stage 5 till all operations are designated to one station.

As per OsuvaEmeka and Aniekan [5], the work load dispersion in any aseemble line can be made uniform by decreasing the quantity of workstations and in this manner killing the unmoving time.

As indicated by Merengo, F Nava and Pozzetti [6] new adjusting and creation sequencing approachs which seek after the accompanying shared objectives, minimizes the rate of deficient jobs(In paced lines and in Moving lines) or the likelihood of blocking/Starvation occasions (In unpaced lines ), lessening WIP.

\section{PROBLEM STATEMENT}

ABC Company has got three shop floors in which shop floor 1 produce Rotary rack broiler (RRO) which procures the significant income for the organization .As specified beneath, the assembling of RRO happens at settled design, that every one of the parts and sub get together conveyed to one spot where complete manufacture and last get together is finished. There B-700 comprise of 114 sections and these can be extensively ordered into three noteworthy segments which are sheet metal parts, structures\& outlines and mechanical and electrical segments.

In a month's term organization can amass just 30 broilers where the objective is to collect 50 stove. Subsequently the test is to decrease the process duration of stove by utilizing IE strategies.

\section{PROJECT OBJECTIVES}

- To convey the work stack consistently.

- To parity the mechanical production system.

- To upgrades the assets (labor).

- To distinguish the squanders and non-esteem included exercises.

\section{PROJECT PLAN}

To do the task work in an ABC Company at first perception of the plant was done and found the region of interest and after that particularly went to the issue to be concentrated upon. Subsequent to getting the issue definition every one of the information were gathered and the information was examined and separate results were gotten and after that gave the answer for the genuine issue.

\section{DATA COLLECTION}

- $\quad$ Time available for work Shift duration $=9 \mathrm{hrs}=540$

Allowance $=60 \mathrm{~min}$ (30 $\mathrm{min}$ for lunch and two tea breaks of $15 \mathrm{~min})=540-480=480 \mathrm{~min}$

- Total task time for one unit, $\mathrm{T}_{\mathrm{t}}=2441$

- $\quad$ Total idle time $=349$

- Total time taken for one unit=2790

- Number of workstation, $m=9$

- $\quad$ Time taken for stage 1- $366 \mathrm{~min}$

- $\quad$ Time taken for stage 2- $219 \mathrm{~min}$

- Time taken for stage 3-112 min

- Time taken for stage 4- $456 \mathrm{~min}$

- Time taken for stage 5- $140 \mathrm{~min}$

- Time taken for stage 6-310 min

- Time taken for stage 7-642 min

- Time taken for stage 8-121 min

- $\quad$ Time taken for stage 9- $75 \mathrm{~min}$ 


\begin{tabular}{|l|l|l|l|}
\hline Stages & $\begin{array}{l}\text { Task } \\
\text { time }\end{array}$ & $\begin{array}{l}\text { Idle } \\
\text { time }\end{array}$ & $\begin{array}{l}\text { Total } \\
\text { time }\end{array}$ \\
\hline 1 & 366 & 72 & 438 \\
\hline 2 & 219 & 28 & 247 \\
\hline 3 & 112 & 20 & 132 \\
\hline 4 & 456 & 78 & 534 \\
\hline 5 & 140 & 22 & 162 \\
\hline 6 & 310 & 40 & 350 \\
\hline 7 & 642 & 66 & 708 \\
\hline 8 & 121 & 18 & 139 \\
\hline 9 & 75 & 5 & 80 \\
\hline & & & 2790 \\
\hline
\end{tabular}

\section{RESULTS}

\subsection{Calculation for Existing 9 Stages}

The highest time taken by a workstation in the assembly line is 708 mins.

Therefore C.T $=708$ mins.

1. Maximum output $=\underline{\text { Available time }}$

$$
\begin{aligned}
& \text { Cycle time } \\
= & 480 \mathrm{~min} / 708 \mathrm{~min} \\
= & 0.678 \text { Units } / \text { day }
\end{aligned}
$$

2. Line efficiency $n=$ sum of task time / (actual no. of workstations* cycle time)

$$
\begin{aligned}
& =2790 / 9 * 70 \\
& =0.437 \\
& =43.07 \%
\end{aligned}
$$

3. Balance Delay $=(\underline{m * C . T})-T$

$$
\mathrm{m} * \mathrm{C} . \mathrm{T}
$$

Where $\mathrm{m}=$ No. of Work stations

C.T $=$ Cycle time

$\mathrm{T}=$ Task time

$=\underline{(9 * 708)-2790}$

$9 * 708$

$=56.2 \%$

\subsection{Grouping the Station}

Grouping is done to the work station till the task time of grouped work station is near to the cycle time of the assembly line, but should never exceed the cycle time(708 $\min )$.

Trial 1: Stages 1 and 2, total task time $=366+219=585$ mins Trial 2: Stages 1,2 and 3 , Task time $=366+219+112=697$ mins
Trial 3: Stages 1,2,3 and 4, Task time $=$ $366+219+112+456=1053$ mins

From the above trials we can see that grouping states 1,2 and 3, we can get the task time of 697 mins, but grouping stages 123 and 4, we can get task time of 1053 mins. Since the task time of grouped worked stations should be less than cycle time of the assembly time, we select trial 2. Similarly grouping is done to remaining work stations and is shown below.

\begin{tabular}{|l|l|l|l|l|}
\hline $\begin{array}{l}\text { Group } \\
\text { No }\end{array}$ & Stages & $\begin{array}{l}\text { No. } \\
\text { workers }\end{array}$ & $\begin{array}{l}\text { Task } \\
\text { time }\end{array}$ & $\begin{array}{l}\text { Idle } \\
\text { time }\end{array}$ \\
\hline 1 & $1,2,3$ & 7 & 697 & 11 \\
\hline 2 & 4,5 & 7 & 596 & 112 \\
\hline 3 & 6 & 3 & 310 & 398 \\
\hline 4 & 7 & 5 & 642 & 66 \\
\hline 5 & 8,9 & 2 & 196 & 512 \\
\hline
\end{tabular}

\subsection{Calculations for grouped work stations}

1. Line efficiency $n=$ sum of task time $/$ (actual no. of workstations* cycle time)

$$
\begin{aligned}
& =\frac{2790}{5 * 708} \\
& =0.790 \\
& =\mathbf{7 9 \%}
\end{aligned}
$$

2. Balance Delay $=(\underline{m * C . T})-\mathrm{T}$

$$
\mathrm{m}^{*} \mathrm{C} . \mathrm{T}
$$

Where $m=$ No. of Work stations

$$
\begin{aligned}
& \text { C.T }=\text { Cycle time } \\
& \begin{aligned}
\mathrm{T} & =\text { Task time } \\
& =\frac{(5 * 708)-2790}{5 * 708} \\
& =\mathbf{2 1 \%}
\end{aligned}
\end{aligned}
$$

The line efficiency after grouping the work station is increased from $43.07 \%$ to $79 \%$. And the balance delay reduces from $56.2 \%$ to $21 \%$. This makes that work load distribution uniform across the workstations which makes the flow of the assembly line much smooth.

\section{CONCLUSION}

Work load in the main assembly line main assembly line Since the sequential construction system in the plant is physically worked and the work apportioned to specialists is in individual stages, there is a ton of time wastage between the workstations which is the explanation behind its high adjusted postponement. By gathering the workstations, the work designated to the laborers are in gatherings and this which has an undertaking time close to the process duration of the get together time. This lessens 
the holding up time between the workstations and decrease the adjusted delay in the mechanical production system. The adjustments in line productivity and adjusted postponement prior and then afterward gathering the workstations is demonstrated as follows.

\begin{tabular}{|c|c|c|}
\hline Fators & $\begin{array}{l}\text { Before groujing } \\
\text { workstetious }\end{array}$ & $\begin{array}{l}\text { After grospugs } \\
\text { wodkstations }\end{array}$ \\
\hline Ine effcenxy & $4207 \%$ & $79 \%$ \\
\hline Balanod dely & 56.24 & $21 \%$ \\
\hline
\end{tabular}

The flow in the assembly line becomes smooth. Due to the results shown above. Hence the work load distribution in terms of grouped workstations is recommended rather than individual workstations.

\section{REFERENCES}

[1]. Scholl, A. and Becker, C. (2006), "State-of-the-art exact and heuristic solution procedures for simple assembly line balancing", European Journal of Operational Research, Vol. 168 No. 3, pp 666-693.

[2]. Sotirios G. DimiTriadis (2006) " Assembly line balancing and group working: A heuristic procedure for worker's groups operating on the same product and workstation", Computers and Operation Research Vol. 33, pp. 2757-2774.

[3]. Nils Boysen and MalteFliedner[2008], “Assembly line balancing," International Journals of production Ecnomics, pp 509-528.

[4]. Helgeson, W. R. and Birnie, D (1961). "Assembly line balancing using the ranked positional weight technique", Journal of industrial engineering, 12, 394-398.

[5]. OsuyaEmeke Great, AnieekanOffiomg. (2013) International Journals of problems and applications in Engineering research- Paper Vol.04, issue 01; pp 22308547 ;

[6]. Merengo, C., Nava, F. and Pozzetti, A. 999,'Balancing and sequencing manual mixed model assembly line,", International Journal of production research, Vol 37 No.12, pp. $2835-2860$. 